\title{
Vehicle diagnostic system of the car engine
}

\author{
Roman Zinko ${ }^{1}$, Oleh Polishchuk ${ }^{2 *}$ Ewa Kulis ${ }^{3}$ \\ ${ }^{1}$ Lviv Polytechnik National University, St.Bandery Street, 12, Lviv, 79013, Ukraine \\ ${ }^{2}$ Khmelnitskyi National University, Instytutska Street, 11, Khmelnytskyi, 29000, Ukraine \\ ${ }^{3}$ Bydgoszcz University of Life Sciences and Technology, Faculty of Mechanical Engineering, \\ Kaliskiego Street 7, 85-796 Bydgoszcz, Poland
}

\begin{abstract}
Support of the established technical characteristics of engines is reached by its regular service and diagnostics in particular - existence of the diagnostic programs built in the onboard computer of the car which carry out constant control of the main parameters of the engine.Based on the algorithm of vibroacoustic diagnostics, a system of vibration and vibroacoustic diagnostics of the internal combustion engine (ICE) is proposed, which can be integrated into the intelligent environment of self diagnostics of the car (Check - Engine). The algorithm takes into account the normalized parameters and criteria for assessing the vibration state: the absolute values of displacements, velocities and accelerations and their changes.For the self-diagnostic system, it is important to develop a classifier of engine states also to determine and / or predict the failure of its parts or units. Engine vibrations can be attributed to the following types: imbalance of the 1 st and 2 nd order of the engine; vibration associated with combustion in the engine; auxiliary units. The analysis of a vibroacoustic signal at work of the serviceable and faulty engine is carried out, influence of various elements of a design, placement of the gauge in horizontal and vertical directions is shown on it.
\end{abstract}

\section{Introduction}

A significant increase in the number of cars is accompanied not only to a man, but also a number of negative consequences, primarily harmful emissions contained in exhaust gases. This leads to increased requirements for car power plants. The main measures are decreased by the specific fuel consumption and reduction of emission of harmful substances contained in the engine's exhaust gases. The solution of these tasks is possible both by improving the design and parameters of the engine itself, and the improvement of its auxiliary systems: preparation and submission of the working mixture in engine cylinders, inflammation, exhaust gases, etc. Another direction in satisfying the growing demands imposed on DVD supporting the established technical characteristics of engines achieved by its regulatory service and diagnostics, in particular - the availability of a computer-based computer programs that make constant control of the main parameters of the engine $[1,2]$. When

\footnotetext{
* Corresponding author : opolishchuk71@gmail.com
} 
detecting the deviation of any parameter from the permissible values, an alarm system is carried out with the help of car self-diagnostics (Check - Engine) [3].

The new world standard in the field of on-board diagnostics ISO 27145 «Road vehicles are currently acquiring. Implementation of World - WIDE HARMONIZED ON - BOARD DIAGNOSTICS ». The ISO 27145 standard includes five parts. ISO 27145-1 "General Information Andusecase Definition" defines the use of on-board diagnostics and its concept.

In the practical diagnosis of machine machines, there are two main approaches to the decision of diagnostic tasks $[4,5]$.

In the first case, the diagnosis is performed only after the detection of changes in the vibration state of the machine by means of monitoring and its task is to interpret these changes. However, as a rule, monitoring is carried out in a low-frequency and mediumfrequency vibration, which responds to the appearance, basically, only developed defects. They lead to significant changes in the energy parameters of vibration, which exceed their natural fluctuations when changing the modes of the machine.

The second approach is to use the methods and means of diagnostics that exhibit the main types of defects at the stage of their origin before the significant energy changes in the vibration signal of the machine as a whole will occur. Detection of defects at the stage of origin makes it possible to observe their development and plan work on repair and maintenance of the machine. This approach is often called defects monitoring.

Normalized parameters are $[6,7,8,9,10]$ : acceleration in $\mathrm{m} / \mathrm{s} 2$, in a frequency range from 2 to $3000 \mathrm{~Hz}$; speed in $\mathrm{mm} / \mathrm{s}$, in the range of frequencies from 2 to $1000 \mathrm{~Hz}$; Moving in $\mu \mathrm{m}$, in the range of frequencies from 2 to $200 \mathrm{~Hz}$. Acceleration measurements in the range of 2 to $3000 \mathrm{~Hz}$ are used to evaluate the vibration state.

For the purpose of in-depth study to identify malfunctions (diagnostics), acceleration measurements in the frequency range up to $10,000 \mathrm{~Hz}$ and higher $[11,12]$ are recommended. If the features of the design of the equipment that created by vibration concentrated in the narrower frequency range, it is allowed to measure broadband vibration in a narrower frequency range, for example, to accelerate - from 10 to $3000 \mathrm{~Hz}$, for a speed - from 10 to $1000 \mathrm{~Hz}$, for moving - from 10 to $200 \mathrm{~Hz}$. In this case, the designation of the measured value is complemented by the range of measurement frequencies.

The standard GOST 32106-2013 [13] Installed two criteria for evaluating vibration status: absolute values of displacements, speeds and accelerations and their changes. The general estimate of the vibration state is determined by the criterion, according to which the vibration state of the equipment is the most dangerous.

Based on the first criterion zone of the vibration state are determined for absolute values of displacements, speeds and accelerations [10].

According to the second criterion, changes in the values of movements, speed and acceleration in one hour [13] are determined.

\section{Presenting main material}

Based on the algorithm of vibroacoustic diagnosis, a system of vibration and vibroacoustic diagnosis of internal combustion engines is proposed, which can be integrated into the intellectual vehicle self-diagnostic environment (Check-Engine).

The algorithm of vibroacoustic diagnostics can be presented in the form of a functional scheme (Fig. 1), which is proposed on the basis of a known scheme [14]. Methods for measuring the engine vibration must have at least two measurement channels, one of which determines the vibration amplitude at the rotational frequency, and the other (channel with a circuit sensor) - its phase relative to the selected label on the crankshaft. When looking for defects, vibration is measured in typical modes of engine operation and in addition to lowfrequency can measure and high-frequency vibration of the support or the engine housing. 


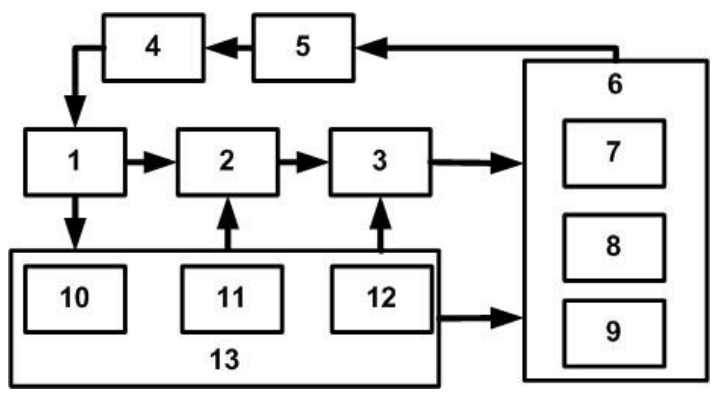

Fig. 1. Functional diagram of technical diagnostics: 1 - object of diagnosis; 2 - diagnostic signals; 3 diagnostic features; 4 - management of the object; 5 - diagnosis (evaluation criteria); 6 - expert system; 7 - classification of features and defects; 8 - set of decisive rules; 9 - system of diagnostic features and defects; 10 - Troubleshooting classes and defects; 11 - matrix of diagnostic features and defects; 12 reference variables of diagnostic features; 13 - diagnostic model.

The amplitudes of oscillations of various elements and engine aggregates have significantly different meanings (for example: fluctuations associated with defects in rolling bearings are many fewer than those caused by various defects, such as imbalance, nondustiness or damage to gear or growing gears) $[5,15,16]$. These defects cause oscillations with amplitudes of different orders, so it is advisable to compare the obtained data with existing reference values for various defects, instead of using the only general level adopted by the level of warning about possible details. Since in practice, it is necessary to deal with different designs and methods of application of parts and aggregates, different rotational frequencies and conditions of their loading, - it is very difficult to install one level of warning, which would work well in all, or even many situations. When they talk about the magnitude of the development of defects, then in the first place binds it with the characteristic features of the spectra $[17,18]$. Image recognition is a key point to determine the stage of development of a defect based on a vibroacoustic picture of the behavior of parts and engine aggregates $[19,20]$.

The proposed block diagram of a vibration and vibroacoustic diagnostic system (Fig. 2), which consists of a measuring system (blocks 2 and 3), diagnostic information processing systems (block 5) and a technical condition recognition system (blocks 6 and 7).

As can be seen from the brought structural scheme, the recognition unit provides the implementation of the final stage of the diagnostic process, the quality and efficiency of which greatly affects the reliability and accuracy of the diagnosis as a whole. Therefore, in the development and implementation of a system of vibroacoustic diagnostics as a component of an integrated monitoring system of DICs, special attention, along with other tasks, should be discussed by the development of a vibroacoustic classifier.

For the system of self-diagnosis it is important to develop a classifier of engine states also to determine and / or predict the failure of its parts or units [21, 22]. Engine vibrations can be attributed to the following types:

1. Unbalance of the 1 st and 2 nd order of the engine;

2. Vibration associated with combustion in the engine;

3. Auxiliary units. 


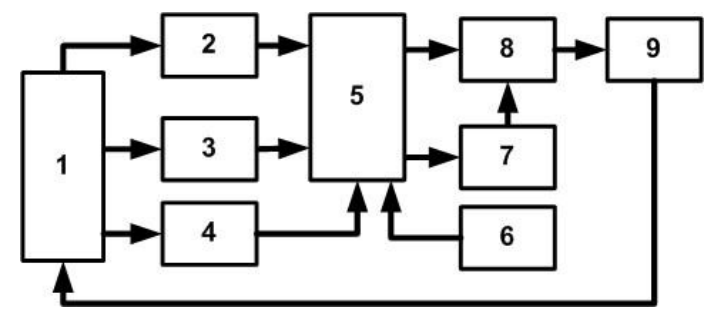

Fig. 2. Functional block diagram of the car self-diagnostic system (Check - Engine): 1 - engine; 2 - unit for measuring vibration and acoustic signals; 3 - unit for measuring the speed of the crankshaft; 4 diagnostic model of the engine; 5 - signal processing unit; 6 - block selection of diagnostic criteria; 7 - block formation of a set of signs and defects; 8 - state classifier; 9 - unit for generating diagnostic results.

1. The order of imbalance refers to the number of imbalance factors during one revolution of the rotating body. For example, if there is only one point of imbalance on the wheel that makes one turn, it is a 1 st order vibration. If there are two unbalanced points, it will be a 2 nd order vibration. The reason for using the order of vibration is to obtain the amount of vibration created by the unbalanced factor, when multiplying the order by the obtained frequency. The speed of rotation of a rotating body, such as a crankshaft, is determined by the engine speed $(\mathrm{rpm} \div 60=\mathrm{Hz})$. In the presence of two unbalanced factors per revolution of the crankshaft rotation, the order of this rotating body becomes a 2 nd order vibration. Based on this, we can calculate that the excitation source has a frequency of $40 \mathrm{~Hz}$ at $1200 \mathrm{rpm}(1200 \mathrm{rpm} \div 60 \times$ 2 (order)). Analyzing the obtained frequency with the help of measuring equipment, the order allows to understand the number of existing unbalanced factors. The calculation of the frequency of the unbalanced factor is very simple and consists in dividing the obtained value of rpm by 60 and multiplying by the value of the order.

1st order motor imbalance vibrations occur if the crankshaft or other parts rotate at the same speed and have an imbalance (mass, shape) or increased wear. A good example is an unbalanced flywheel or cylinder balancer. Rarely, but sometimes the crankshaft itself can be unbalanced. In this case, the vibration of the engine can be eliminated by restoring the balance between the components or eliminating wear. In addition, the vibration of the 1st order of the engine components can be eliminated by adjusting the counterweights on the crankshaft.

The vibration of the imbalance of the engine of the 2 nd order can additionally be the movement of the piston. The mass of the piston and its movement inevitably create vibration.

Signs of engine imbalance: shaking (vibration) at low speed is felt at a frequency of 480 to $1200 \mathrm{rpm}(8-20 \mathrm{~Hz})$; strong vibration or noise is felt at a frequency of 1200 to $3000 \mathrm{rpm}$ (20-50 Hz).

The imbalance of the 1st and 2nd order in the engine is usually determined during engine warm-up at idle.

2. The combustion frequency in the engine refers to the frequency of vibration resulting from the combustion of fuel inside the cylinder. This frequency can be different and depends on the number of cylinders in the engine. At one rotation of a cranked shaft combustion is carried out only in half of cylinders. If one combustion chamber is defined as an imbalance factor, it can be considered as 0.5 imbalance factor per revolution of the crankshaft. In other words, half of all engine cylinders are the order of vibration of the engine. For example, on a 4-cylinder engine, combustion occurs in the 2 nd and 4 th cylinders during one revolution of the crankshaft, ie the vibration order for this engine is $2(4$ cylinders $\div 2=2)$. On a 6 -cylinder engine, the combustion order in the engine is 3 .

3. All auxiliary units driven by the engine by means of a belt or gear transmission can experience vibration at each turn of a cranked shaft. In the event of noise and vibration, in 
order to determine the device that is the source of vibration, it is enough to remove the drive belt and start the engine. Measure the vibration level. Then set the belt in place and test each device separately to determine the main source of vibration. For example, you can turn on / off the air conditioner. To test the power steering, a good test is to turn the steering wheel.

In addition, misalignment or modification of the pulley can cause vibration of auxiliary equipment. In the case of air conditioning systems, overload or vulnerability to high oil content can also lead to abnormal operation. These vibrations must be compared with the presence of vibrations on a working car.

The engine mounting and gearbox must support the engine and insulate the body from engine vibration. In order to absorb the engine rotation caused by the transmission of force through the power drive, the mounting must be relatively rigid. However, in order to reduce the vibrations transmitted to the car body from the road surface through the tires, wheels and powertrain, the mount must be relatively soft at the same time to absorb a certain level of vibration. For this reason, in order to meet both requirements at the same time, liquid-filled and electronically controlled fastening systems have been developed and implemented. At the same time, rubber supports are used.

Tasks of fastening of the engine: provides fastening of the engine and transmission to a body and supports weight; absorbs the vibration transmitted from the engine to the car body; eliminates certain behavior of the engine and transmission when transmitting force and absorbs shocks coming from the road surface.

In fig. Figure 3 shows a typical graph of the relationship between the vibration frequency of the components $(\mathrm{Hz})$ and the frequency level $(\mathrm{dB})$. If you look at the data, the horizontal axis means the frequency component of the obtained data. The vertical axis reflects the level of vibration of each frequency component. The vibration frequency range of the components felt by passengers is usually below $300 \mathrm{~Hz}$. Higher frequency vibrations are rarely felt by humans, but can be transmitted to passengers in the form of noise. On the graph, you can see that the left side of the dotted line, due to the nature of the frequency of the equipment, will change slightly with each measurement and therefore it can be ignored (below $4 \mathrm{~Hz}$ ). At the same time, the components with a high frequency $(\mathrm{dB})$ on the left side of the dotted line are targets that need to be confirmed. As shown in the graph above, components with a frequency of $11.7 \mathrm{~Hz}$ show a level of $104 \mathrm{~dB}$ compared to other frequencies. This frequency is the main target object that can be used to determine the source of excitation. As already mentioned, measurements should be made in the area where the signs of vibration are most obvious. The reason is that if the data obtained from the measurements made at the point where there is no vibration will have the highest level of $\mathrm{dB}$ in the graph above, there is a high probability that this is not a real source of vibration.

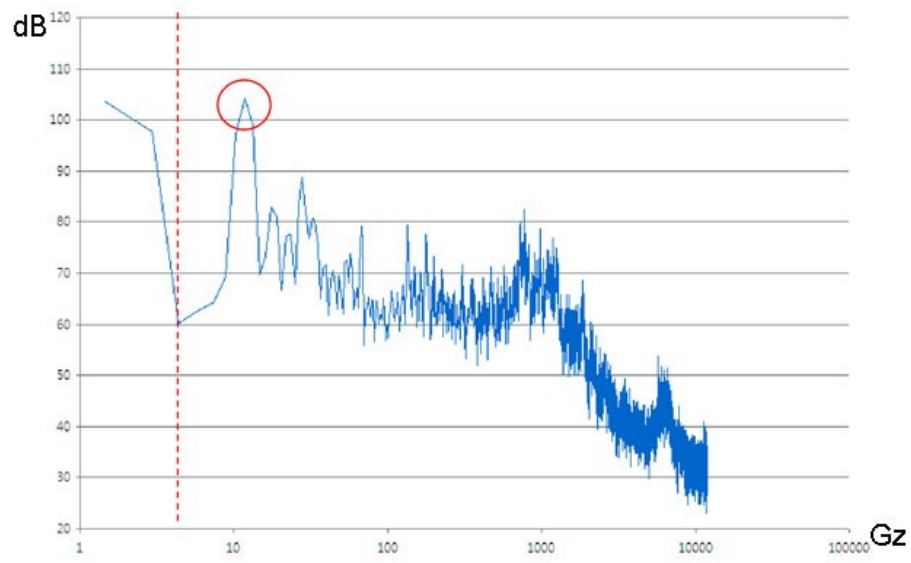

Fig. 3. A typical graph of the relationship between the vibration frequency of the components $(\mathrm{Hz})$ 
and the frequency level (dB).

Using the obtained data and the engine speed during vibration, we can determine the part of the engine that creates vibration [23]. For example, according to the graph above, if the engine speed during the measurement is $700 \mathrm{rpm}$, you can calculate the frequency of each order on the engine and the frequency of each unit. For the 1 st order frequency on the motor, it is equal to $700 \div 60=11.6 \mathrm{~Hz}$, and for the $2 \mathrm{nd}$ order frequency, it is equal to $23.2 \mathrm{~Hz}$. It can be confirmed that the frequency of the component having the highest vibration level (dB) on the graph is identical to the 1st order of the vibration frequency of the motor. The source of the 1st vibration level of the engine becomes the target source of excitation, and the vibrations emanating from it are transmitted to the passengers inside the car through a resonant system, body or transmission system, such as the suspension. Usually, if there is vibration in the engine, the vibration of the engine component associated with combustion is also probable ( 4 cylinders - 2nd order). In this regard, we can assume that there is a certain factor that creates a significant vibration of the 1 st order in the engine. It is necessary to carefully check the parts that create a vibration of the 1 st order.

Point A (Fig. 4) is the frequency range of the motor that has no vibration at $1000 \mathrm{rpm}$. Point $\mathrm{B}$ displays the frequency range if the shift lever of the automatic transmission is moved to position $\mathrm{D}$ (Drive) from the initial position $\mathrm{N}$ (point $\mathrm{A}$ ). If the frequency falls below the normal level and the $\mathrm{dB}$ increases, it means that the vibration increases simultaneously with the decrease of the engine speed. The part marked with points $\mathrm{A}$ and $\mathrm{B}$ has the highest level of $\mathrm{dB}(104.39 \mathrm{~dB})$ according to the waveform specified above. This means that this zone has the highest amplitude among the vibrating components, and vibration occurs in this range of vibrations. Thus, the vibration occurs in the highest range of $\mathrm{dB}$.

The frequency shown in the form of a signal (Fig. 5) is equal to $33.69 \mathrm{~Hz}$. If the waveform is measured on a car, it means that the vibration occurred under the action of a forced vibrating body (vibration force) with a frequency of $33.69 \mathrm{~Hz}$. Thus, it is necessary to find a forced vibrating body in this range of vibration. The found body will most likely be a source of vibration that requires repair.

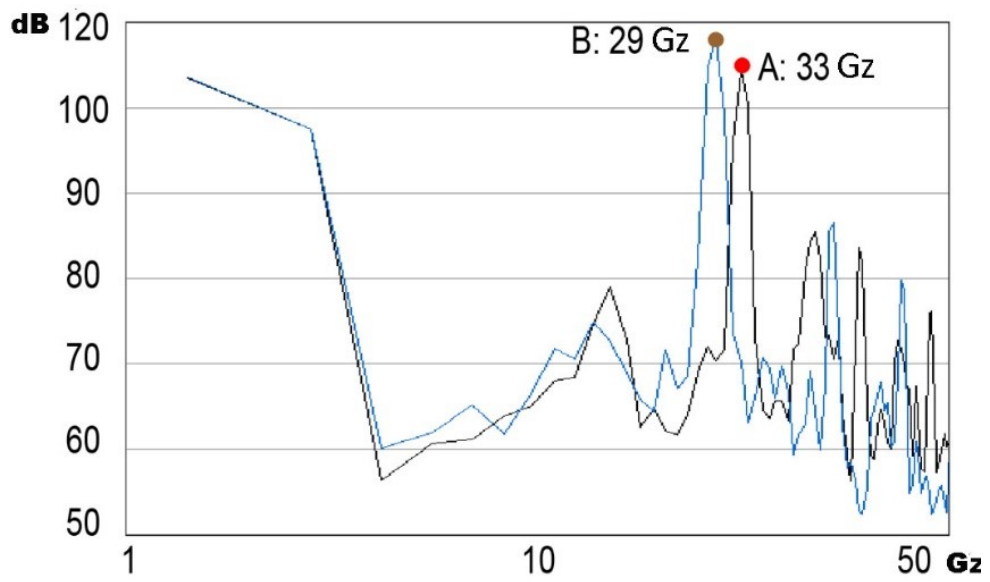

Fig. 4. Change of size of vibrations depending on operating modes of the engine.

When switching the gearshift lever to the driving mode on a parked car, the load is transferred to the engine. Usually, motors compensate for the increase in engine speed, so engine vibration is rare. However, in the event of a power imbalance, the engine speed drops and the engine vibrates. Then this vibration is transmitted to the car body. If the engine mount absorbs vibration, it does not reach the body. However, if it exceeds the absorption limits, 
the vibration is transmitted to the car body. If vibration is transmitted to the car body, you can check whether it is due to an imbalance in the engine or mounting by measuring the vibration frequency and $\mathrm{dB}$ level.

When considering low-frequency vibrations, the bottom line of the waveform in the graph above reflects the vibration frequency and the $\mathrm{dB}$ value at $1000 \mathrm{rpm}$ with a working engine. The upper bottom line of the waveform on the graph above shows the vibration frequency and the $\mathrm{dB}$ value when the engine is faulty under the same conditions.

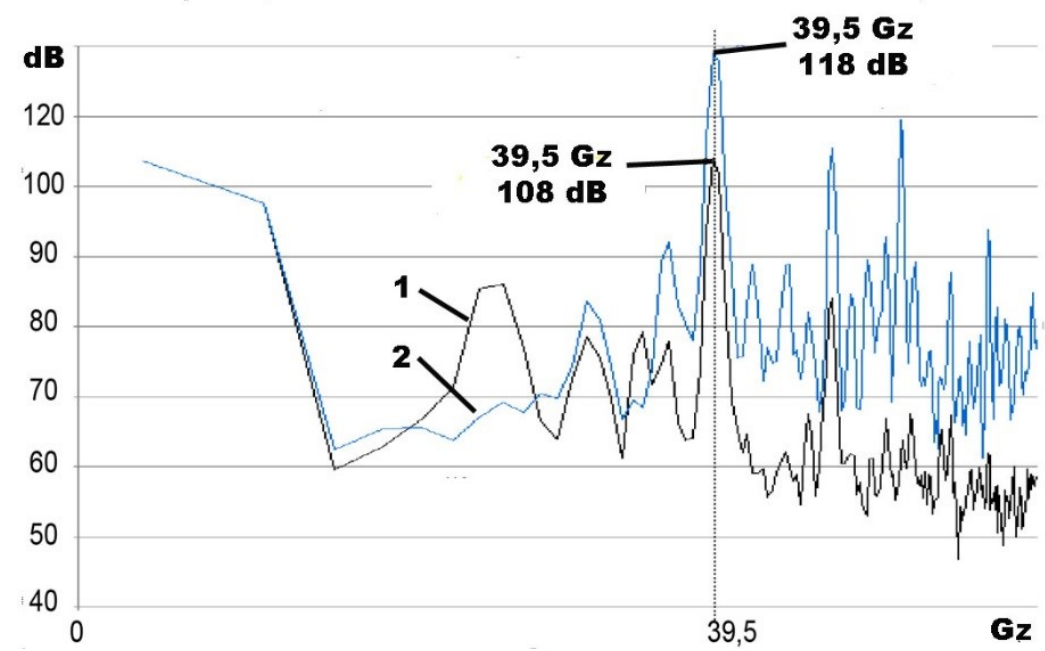

Fig. 5. Changing the magnitude of low-frequency vibrations with a faulty (1) and serviceable (2) engine.

The frequency range in faulty and serviceable mode does not change, while only the value of $\mathrm{dB}$ changes. When the value of $\mathrm{dB}$ and the constant frequency of vibration change, the amplitude of the motor changes (forced vibrating body). This is not a problem for the engine, however, as a result, the engine mount cannot properly absorb vibration. Changing the frequency can be seen as a problem of motor imbalance. If this is a problem with the motor imbalance, the $\mathrm{dB}$ value will change with the change in frequency and amplitude.

The vibroacoustic signal adequately reflects the operation of the valves (Fig. 6), ie the vibroacoustic signal reflects the dynamics of the engine and pressure changes in the inlet manifold $[24,25]$. Therefore, the analysis of the vibroacoustic signal allows to visually and reliably assess the condition of the engine and its mechanisms.

The use of acceleration can be a good means of identifying defects that are accompanied by oscillations with very small amplitudes, if we consider not the spectral but the temporal shape of the signal $[26,27]$. The use of acceleration, in whatever form it is displayed temporal or spectral - provides an exponential increase in amplitude with increasing frequency. Therefore, having at their disposal data of low-amplitude high-frequency components, obtained in the form of vibration acceleration signals, it is possible to determine the characteristic types of defects of engine parts. 


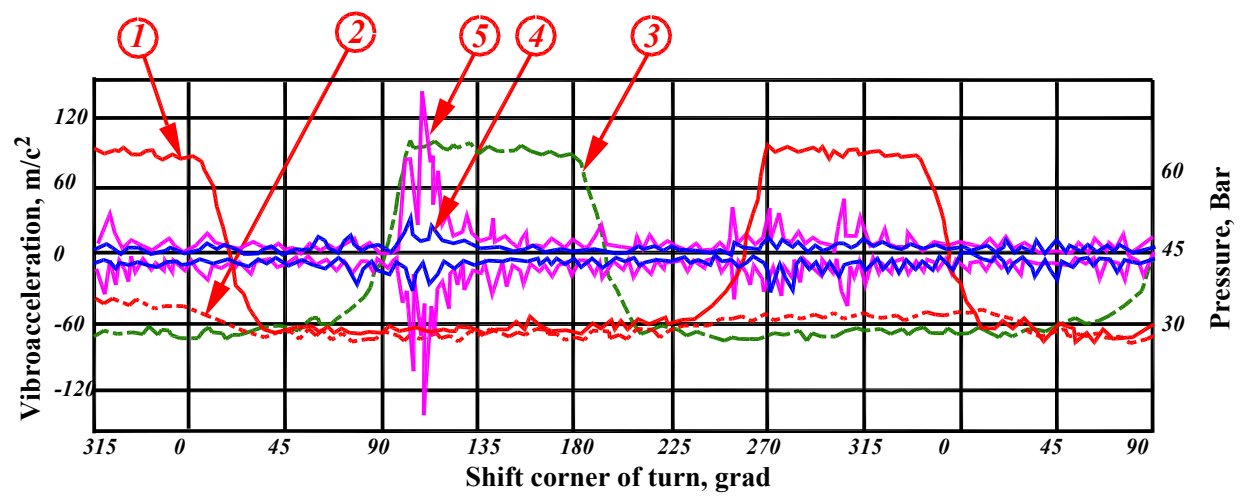

Fig. 6. Vibration (4) and pressure (1), (3) in the cylinder with serviceable valves; vibration (5) and pressure (2), (3) in the cylinder with a faulty valve

In fig. 7 shows the vibration of the housing at the place of installation of the motor bearings in the horizontal and vertical directions with increased vibration in the high frequency range $(800 \ldots 2000) \mathrm{Hz}$.
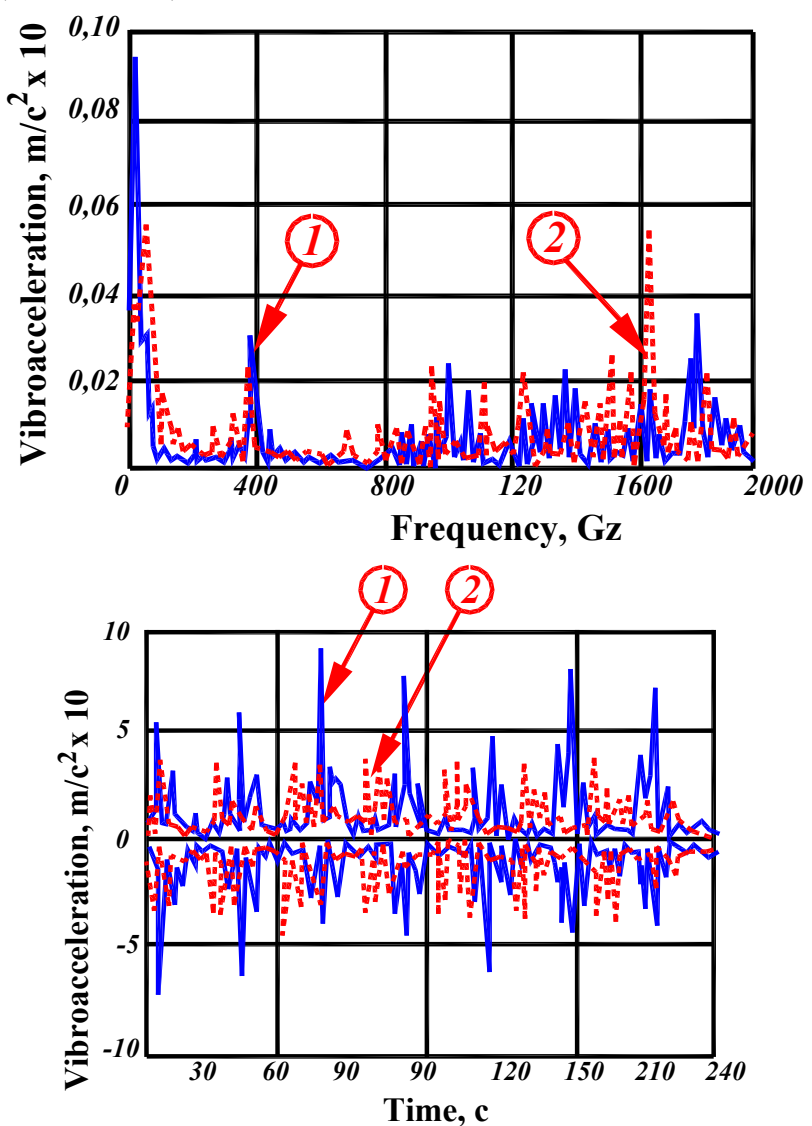

Fig. 7. The engine vibration spectrum is measured in vertical (1) and horizontal (2) direction with increased vibration in the high-frequency range $(800 \ldots 2000) \mathrm{Hz}$ 


\section{Conclusions}

Based on the algorithm of vibroacoustic diagnostics, a system of vibration and vibroacoustic diagnostics of DICs is proposed, which can be integrated into the intellectual self-diagnosis of the car (Check - Engine). The algorithm takes into account the normalized parameters and criteria for assessing the vibration state: absolute values of displacements, speeds and accelerations and their changes.

For self-diagnostics, it is important to develop a classifier of engine states as well as to determine and / or predict the breakage of its details or aggregates. Engine vibrations can be attributed to the following types: imbalance of the 1st and 2nd engine order; vibration associated with the engine combustion; Auxiliary aggregates.

The analysis of the vibroacoustic signal during the work of a proper and faulty engine is carried out, the influence of the various elements of the design, placement of the sensor in horizontal and vertical oppression is shown.

\section{References}

1. V.V.Bulanov. Reconsignment reconsideration with vibro-diagnostics of construction machinery / V.V. Bulanov, V.I. Klymenko // Bulletin of the Kharkiv National Automobile and Highway University: collection of scientific works - Kharkiv, 2007. - Push. 37. - P. 57-59.

2. D.M.Baranovskyi. Construction of a mathematical model of dynamic diagnostics of the technical condition of cars / D.M. Baranovskyi, S.O. Khoryshman // New Technologies. - 2012. - № 4. - P. 88-90.

3. S.V.Pletnev., Yu.V.Kriukov., A.B.Ferenets, A.A.Shevchenko. Diagnosting of a cargo car engine on the basis of technologies ODX// Westman of the Kazakh State Technical University IM. A.N. Tipole. - № 2, 2014. - P. 58-61.

4. Non-stroke control [Text]: handbook in 7 volumes. Volume 7. In 2 books. Book 2 Vibroacoustic diagnosis / F.Ya. Balytskyi, A.V. Barkov, N.A. Barkova [et al.]; под общ. ред. V.V. Kliueva. - M. : Mechanical engineering, 2005. - 829 p.

5. A.P.Naumenko. Methodology of vibroacoustic diagnostics of piston machines [Text] / A.P. Naumenko / Bulletin MGTU them. N.E. Bauman. Spec. Vol. Ser. «Mechanical engineering». - M. : MSTU them. N.E. Bauman, 2007. - P. 85-95.

6. GOST 14846-81 (ST SAV 765-77). Automobile engines. Methods of bench tests. 1981.

7. Technical diagnostics. The main terms and definitions: GOST 20911-89. - M.: Publishing house standards, 1990. - $13 \mathrm{p}$.

8. ISO 10816-6:1995 Mechanical vibration - Evaluation of machine vibration by measurement on non-rotating parts - Part 6: Reciprocating machines with power ratings above $100 \mathrm{~kW}$. International Organization for Standardization. Printed in Switzerland, 1995. $-9 \mathrm{p}$.

9. GOST R ISO 10816-1-97 vibration. Monitoring the state of the machines according to the results of vibration measurements on the unwilling parts. Part 1. General requirements [Text]. - Introduction 1999-07-01. - M.: IPC Publishing House Standards, 1998. - $14 \mathrm{p}$.

10. GOST R ISO 10816-3-99. Vibration. Assessment of the state of the machines according to the results of vibration measurements on non-rotating parts [Text]: Ch. 3. - Introduction 2000-07-01. - M.: IPC Publishing House Standards, 2000. - 10 p.

11. v.N.Kostiukov. Practical basics of vibroacoustic diagnostics of machinery [Text]: studies. Manual / V.N. Kostiukov, A.P. Naumenko. - Omsk: ed, OMGTU, 2002. - 108 p. 
12. D.Lynn. Detection of rolling bearings defects using vibration analysis / Computational Systems, Inc. (CSI) per. with English I.R. Sheiniaka, edited by V.A. Smirnova. http://www.vibration.ru/v_defekt.shtml.

13. ГОСТ 32106-2013. Condition monitoring and diagnostics of machines. Hazardous equipment monitoring. Vibration generated by rotodynamic pump and compressor units. 2013.

14. G. Modgil, R. Orsagh, and M. J. Roemer, "Advanced vibration diagnostics for engine test cells, 2004 IEEE Aerosp. Conf. Proc. (IEEE Cat. No.04TH8720), vol. 5, pp. 3361-3371, 2004.

15. I.Mckinnon. Update International, Inc. Practical approach to analyzing the state of reciprocating machines / lane. with English I.R. Sheiniaka, ed. Cand. tehn Sciences V.A. Smirnova // Vibrodiagnostics for beginners and specialists. URL: http://www.vibration.ru/analiz_mashin.shtml (Date of handling: 05/10/2010).

16. J. Pauli, V. Rabe, On-board diagnostics. Driving down costs and complexity for all vehicles. - Genève Switzerland: ISO Central Secretariat, ISO Focus+, Volume 3, No. 2, 2012. - C. 34-37.

17. K.Elbhbah., J.K.Sinha. Vibration-based condition monitoring of rotating machines using a machine composite spectrum, Journal of Sound and Vibration 332, 2013.

18. DCapriglione., C.Liguori, C.Pianese, and A.Pietrosanto. On-line sensor fault detection, isolation, and accommodation in automotive engines. IEEE Trans. Instrument. Measure., 2003, 52(4), 1182-1189.

19. A.S.Havriukov. On-board neurosystems for determining emergency modes of agricultural machinery / A.S. Havriukov // Vibrations in technology and technologies. - 2004. - №2 (34). - p.48-49.

20. P.Czech, B.Lazarz, H.Madej, G.Wojnar. Vibration diagnosis of car motor engines, Acta Tech. t. 3 fasc. 1, pp. 37-42, Corviniensis - Bull. Eng. 2010.

21. D.Antory, U.Kruger, G.Irwin, and G.McCullough. Fault diagnosis in internal combustion engines using non-linear multivariate statistics. Proc. IMechE, Part I: J. Systems and Control Engineering, 2005, 219(4), 243-258. DOI: $10.1243 / 095965105 X 9614$.

22. X.Wang., U.Kruger, G.W.Irwin, G.McCullough, and N.McDowell. Nonlinear PCA with the local approach for diesel engine fault detection and diagnosis. IEEE Trans. Contr. Sys. Tech., 2008, 16(1), 122-129.

23. M.Desbazeille, R.B.Randall, F.Guillet, M.El Badaoui, and C.Hoisnard. Model-based diagnosis of large diesel engines based on angular speed variations of the crankshaft. Mech. Sys. Sig. Process., 2010, 24(5), 1529-1541.

24. A.Mohammadpour. Survey on Diagnostics Methods for Automotive Engines, American Control Conference, p985-990, 2011.

25. A.Zamanian. Internal Combustion Engine Fault Diagnosis Using Vibration Signals, MSc Dissertation, Tehran University, 2007.

26. A.V.Kostiukov. The orthogonality of the parameters of vibration, vibration and vibrationing in vibrational problems [Text] / A.V. Kostiukov, v.N. Kostiukov // Control. Diagnostics. - 2008. - № 11. - P. 6-15.

27. J.Piecha, T.Ed.Grzyn. Research of the vibration in 3 axes of car body for different idle gear rotational speed, Transactions on Transport Systems, Telematics and Safety, [in:] Burdzik, R., Gliwice: Silesian University of Technology Academic Press, 2011. P. 203-214. 